\title{
Study on Vibration Control of Double Motor Refrigeration Unit in Nuclear Power Plant
}

\author{
Yuan Liang, a , Zhan Shuwen², b, Chen Heyang, c, Bai Jinchuan ${ }^{1, d}$, Cai Rui ${ }^{2, \text { e }}$, Kong Xiangyong, f, Xu Zhangnan ${ }^{1, g^{*}}$ \\ ${ }^{1}$ Suzhou Thermal Engineering Research Institute Co., Ltd Shenzhen, Guangdong Province, China \\ ${ }^{2}$ Yangjiang Nuclear Power Co., Ltd, Yangjiang, Guangdong Province, China
}

\begin{abstract}
In order to solve the problem of excessive vibration during the operation of the refrigeration unit in nuclear power plant, taking the double motor refrigeration unit in operation as the research object, we studied the effective measures to reduce the vibration and improve the stiffness of the double motors in the near resonance region. On the basis of theoretical calculation, the weaknesses of the equipment stiffness were reinforced and reconstructed, and the secondary analysis and calculation of the stiffness and seismic performance of the reformed refrigeration unit were carried out to determine the feasibility of the optimization scheme. Based on the analysis, we optimized the equipment. After that, there was a significant decrease in the vibration of the refrigeration unit. The vibration measurement results indicated that the vibration value of the unit has dropped to the qualified range, effectively avoiding the equipment damage caused by excessive vibration. We provided a complete set of analysis ideas for the research and solution of vibration problems of rotating equipment in nuclear power plant.
\end{abstract}

\section{Preface}

Problems such as high vibration, large fluctuation and bearing failure frequently occur in the refrigeration unit of chilled water system in electrical building of CPR1000 Nuclear Power Plant during daily operation and commissioning. During the operation of the chiller, excessive vibration often occurs, giving rise to such threats as components wear, loose bolts and bearing supports, and fatigue damage of components, which will produce great safety risks.

Modal analysis is a method to study the dynamic characteristics of structures, which is generally used in engineering vibration. Among them, mode represents the natural vibration characteristics of mechanical structure, and each mode has a specific natural frequency, damping ratio and mode shape ${ }^{[1]}$. Harmonic response analysis is applied to determining the steady-state response of a linear structure under sinusoidal (simple harmonic) load varying with time. During the analysis, only the stable forced vibration of the structure is calculated, and the transient vibration at the beginning of excitation is not considered. The purpose of harmonic response analysis is to calculate the response value (usually displacement) versus frequency curve of structure at several frequencies. In this analysis, the purpose of modal analysis and harmonic response analysis is to find out the resonance frequency of the equipment, and their calculation conclusions should be qualitatively corresponding

The safety level of the cold water unit is RCC-M3, and the seismic category is class 1 . The seismic grade of passive equipment such as evaporator, condenser and support frame belong to $1 \mathrm{~F}$; the seismic grade of active equipment such as compressor, motor and coupling of chiller is $1 \mathrm{~A}^{[2]}$. In this paper, we analyze the anti-seismic performance of evaporator, condenser, oil separator and bracket, adopt RCC-M code C3300 to evaluate the stress of the equipment, which proves that the strength of the equipment meets the requirements of the code.

\section{Modal analysis of refrigeration unit}

\subsection{Computational modal analysis theory}

Modal analysis, as an analysis method, is widely used in the vibration engineering. The natural frequencies and modes obtained by modal analysis are the key parameters to analyze the vibration and dynamic characteristics of mechanical structures ${ }^{[3]}$. It also serves as the key basis for mechanical dynamic optimization, fault diagnosis and noise control, so modal analysis has a wide range of applications in practical engineering problems, and plays an irreplaceable important role ${ }^{[4,5]}$.

The basic principle of computational modal analysis: firstly, establish the differential equations of motion of linear time invariant system, and then replace the physical coordinates in the equations with modal coordinates, so that the independent equations described by $\mathrm{N}$ modal coordinate parameters can be obtained. After that, we can

\footnotetext{
${ }^{*}$ Corresponding author: ${ }^{\mathrm{g}}$ email: P196463@egnpc.com.cn aemail: yuanliang@cgnpc.com.cn, bemail: zhanshuwen@crnpc.com.cn, ${ }^{c} e m a i l:$ chenheyang@cgnpc.com.cn,

demail:baijinchuan@cgnpc.com.cn, email:cairui@cgnpc.com.cn, ${ }^{\mathrm{f} e m a i l}$. kongxiangyong@ecgnpc.com.cn
} 
obtain the modal parameters of the system by solving the $\mathrm{N}$ equations by mathematical method. ${ }^{[6]}$.

According to the theory of vibration analysis, the vibration differential equation of an N DOF linear system is:

$$
M \ddot{X}(t)+C \dot{X}(t)+K X(t)=F(t)
$$

Where, $M$ represents the mass matrix of the system, $\mathrm{K}$ represents the stiffness matrix of the system, $X(T)$ is the displacement response matrix of each point of the system, and $F(t)$ is the excitation vector of the system. In general, equation (1) is a coupled system of equations. When there are more degrees of freedom in the system, it will be very complicated or even impossible to solve the equations.

The actual structure can be regarded as undamped free vibration in many cases, and its motion differential equation can be simplified as:

$$
M \ddot{X}(t)+K X(t)=0
$$

The solution of equation (2) is in the form:

$x(t)=X \sin (\omega t+\psi)$

Take equation (3) into equation (2):

$\left(K-\omega^{2} M\right) X=0$

When the system is in the state of free vibration, the amplitude response of each node in the structure is not all zero, so equation (4) must have a non-zero solution, so:

$$
\left|K-\omega^{2} M\right|=0
$$

After solving equation (5), we can get $\mathrm{N}$ eigenvalues $\omega_{r}^{2}(r=1,2, \ldots N)$, then arrange $\omega_{r}$ from small to large, we can obtain that $\omega_{1} \leq \omega_{2} \leq \cdots \leq \omega_{r} \leq$ $\omega_{N}$. The value of $\omega_{i}$ represents the natural frequency of the stage $i$, and the eigenvector $U_{i}$ corresponding to the eigenvalue $\omega_{i}$ is the mode shape of stage $\mathrm{i}$ in the system.

\subsection{Establishment of modal analysis model}

\subsubsection{Geometric configuration}

The water chiller is mainly composed of condenser, evaporator, oil separation tank, compressor, motor, coupling, control cabinet and other components.

\subsubsection{Finite element model}

The external structure is mainly simulated by unit SOLSH190, and the geometric discontinuous area is mainly simulated by unit SOLD185 element. The finite element model is shown in figure1.

\subsubsection{Model loads and boundary conditions}

According to the analysis requirements, the loads to be considered in the strength analysis of water chillers include: dead weight, pressure, design temperature, seismic load and other loads. The equipment is installed on the base through bolts, and the displacement is imposed on the bolt to constrain the displacement in $\mathrm{X}, \mathrm{y}$ and $\mathrm{Z}$ directions, and the vertical constraint has to be put on the contact surface between the equipment support floor and the base.

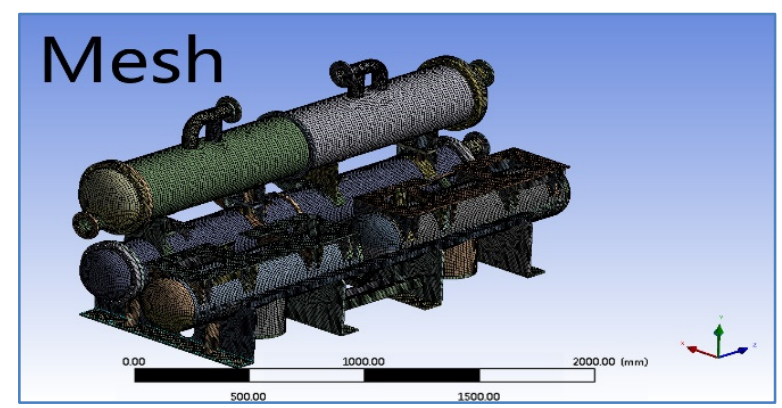

Figure 1 Overall finite element model

\subsection{Modal analysis}

The modal analysis of the chiller is carried out, and a total of 20 modes are calculated. This analysis mainly focuses on the resonance of the equipment caused by the motor. The modal analysis centers on the modal conditions of the components related to the oil separation tank. The modal conditions related to the oil separation tank and its components are shown in figure 2 to figure 3

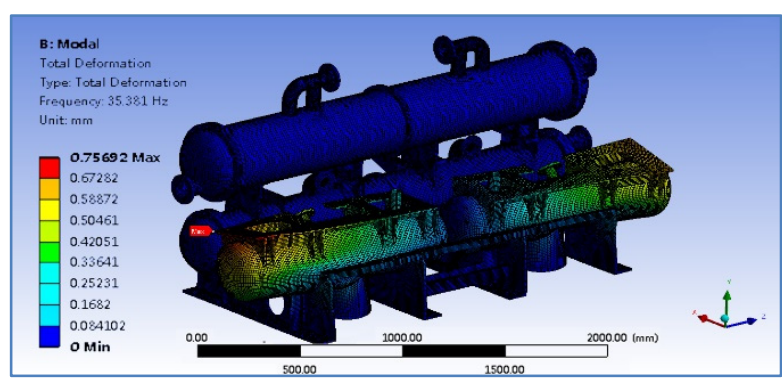

Figure 2 the first-order mode

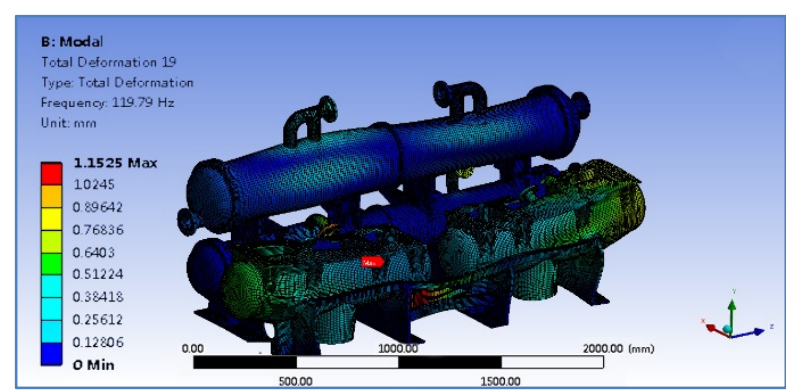

Figure 3 the nineteenth-order mode

\subsection{Modal analysis verification}

According to the modal analysis results of simulation calculation, the lower order modes are mainly concentrated in the oil separation tank, compressor, motor and unit support parts. Therefore, the modal measurement points are mainly set in the above areas. After the modal test, the natural frequency of the equipment is measured, and the experimental results are shown in table 1. By comparing the analysis results with the experimental results, we can see that they are basically the same. The field knocking test MBND-1 corresponds to the first mode of modal analysis, the experimental data of MBND-2 corresponds to the fifth mode, and the experimental data of MBND-3 corresponds to the third mode. 
Table 1 Knocking test results

\begin{tabular}{|c|c|c|c|c|c|}
\hline Equipment & MBND-1 & MBND-2 & MBND-1 & $\begin{array}{c}\text { MBND- } \\
2\end{array}$ & $\begin{array}{c}\text { MBND- } \\
3\end{array}$ \\
\hline $\begin{array}{c}\text { Refrigerator } \\
\text { motor 1 }\end{array}$ & $32.8 \mathrm{~Hz}$ & $116.9 \mathrm{~Hz}$ & $33.1 \mathrm{~Hz}$ & $146.8 \mathrm{~Hz}$ & $68.8 \mathrm{~Hz}$ \\
\hline $\begin{array}{c}\text { Refrigerator } \\
\text { motor 2 }\end{array}$ & $32.5 \mathrm{~Hz}$ & $117 \mathrm{~Hz}$ & $34.4 \mathrm{~Hz}$ & $93.8 \mathrm{~Hz}$ & $68.1 \mathrm{~Hz}$ \\
\hline $\begin{array}{c}\text { Refrigerator } \\
\text { motor 3 }\end{array}$ & $35.7 \mathrm{~Hz}$ & $125.7 \mathrm{~Hz}$ & $35.8 \mathrm{~Hz}$ & $148.7 \mathrm{~Hz}$ & \\
\hline $\begin{array}{c}\text { Refrigerator } \\
\text { motor 4 }\end{array}$ & $33.2 \mathrm{~Hz}$ & $123.1 \mathrm{~Hz}$ & $33.1 \mathrm{~Hz}$ & $146.8 \mathrm{~Hz}$ & \\
\hline
\end{tabular}

\section{Harmonic response analysis}

\subsection{Load application}

The load generated by motor, compressor and other rotating equipment is usually sinusoidal (simple harmonic) with time. In order to find out the resonance frequency band of the water chiller and analyze the influence of simple harmonic vibration on the equipment, the harmonic response of the equipment is also analyzed. Unit loads $(1000 \mathrm{~N})$ in $\mathrm{X}, \mathrm{Y}$ and $\mathrm{Z}$ directions are applied to the center of the four bolt holes of the motor.

\subsection{Analysis of harmonic response results}

The working frequency of the motor is about $50 \mathrm{~Hz}(30 \mathrm{~Hz}$ to $70 \mathrm{~Hz}$ ). After analyzing the harmonic response of the chiller ranges from $0 \mathrm{~Hz}$ to $120 \mathrm{~Hz}$, we can extract the displacement response results of the motor mounting support, as shown in figure 3-1 to figure 3-3.

\subsection{Harmonic response analysis results}

The possible causes of vibration of diagnostic equipment can be seen from figure 3-2 to figure 3-4:

(1) The results of harmonic response analysis are basically consistent with those of spectrum analysis, and the maximum frequency band of harmonic response is located in the corresponding frequency band of each mode of the equipment.

(2) When the harmonic load of $1000 \mathrm{~N}$ is added to the direction $\mathrm{X}$, the displacement response of the motor base $(36 \mathrm{HzX})$ reaches the maximum value of $0.56 \mathrm{~mm}$.

(3) When the harmonic load of $1000 \mathrm{~N}$ is applied in direction $\mathrm{Y}$, the displacement response of motor base has a peak at $36 \mathrm{~Hz}$, and the response displacement is 0.004 $\mathrm{mm}$. When the harmonic load reaches $100 \mathrm{~Hz}$, the response displacement increases gradually.

(4) When the harmonic load of $1000 \mathrm{~N}$ is applied in direction $\mathrm{Z}$, the displacement response of motor base $(48 \mathrm{~Hz})$ reaches $0.03 \mathrm{~mm}$.

(5) Under the same load, direction $\mathrm{X}$ shows the largest response displacement, which indicates that the overall stiffness of the equipment in direction $\mathrm{X}$ is the smallest, followed by direction $\mathrm{Z}$, and the largest one is in direction Y.

\section{Equipment stiffness analysis}

According to the harmonic response analysis in Chapter 3, the overall stiffness of the equipment in direction $\mathrm{X}$ is small, while the displacement response is large. Now the overall stiffness of the equipment is analyzed quantitatively. The static load of $1000 \mathrm{~N}$ in directions X, Y and $\mathrm{Z}$ is applied to the center of the four bolt holes of the motor.

\subsection{Deformation results}

After calculating the overall deformation of the equipment, we can extract the deformation results of the motor base in the direction of load, as shown in figure 4 to Figure 6.

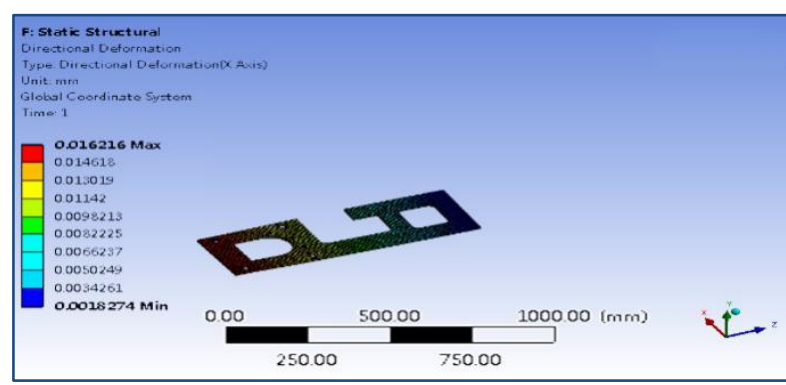

Figure 4 X-direction deformation

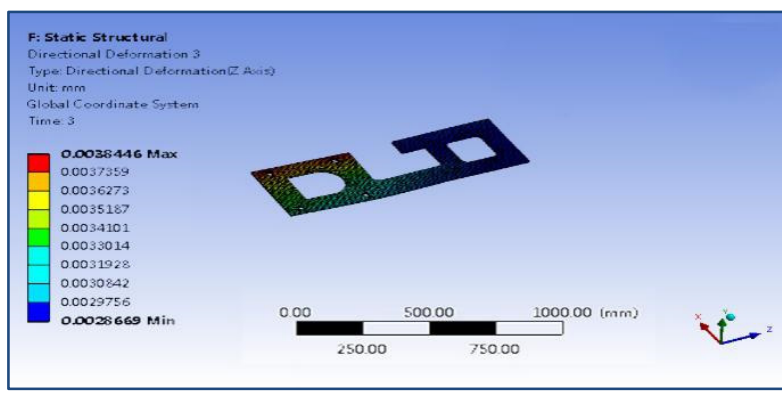

Figure5 Y-direction deformation

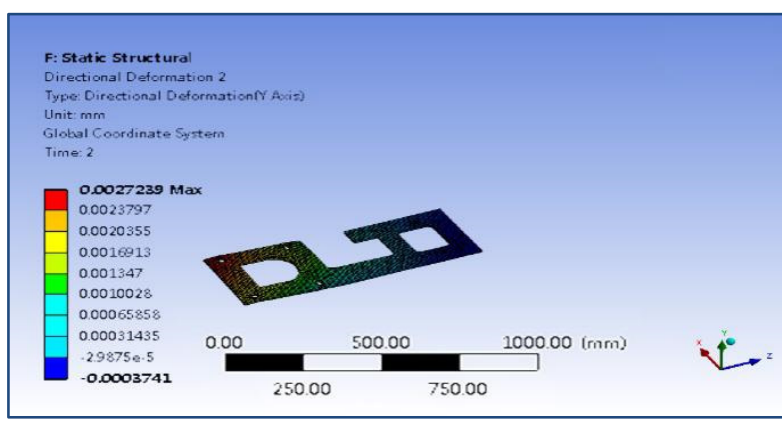

Figure 6 Z-direction deformation

\subsection{Stiffness calculation}

The calculation of the stiffness of equipment in each direction, as shown in table 2.

Figure 2 The stiffness of equipment

\begin{tabular}{|c|c|c|c|}
\hline Direction & $\begin{array}{c}\text { Load } \\
(\mathrm{N})\end{array}$ & $\begin{array}{c}\text { Maximum displacement } \\
(\mathrm{mm})\end{array}$ & $\begin{array}{c}\text { Stiffness } \\
(\mathrm{KN} / \mathrm{mm})\end{array}$ \\
\hline
\end{tabular}




\begin{tabular}{|c|c|c|c|}
\hline $\mathrm{X}$ & 1000 & 0.016 & 62.50 \\
\hline $\mathrm{Y}$ & 1000 & 0.003 & 333.33 \\
\hline $\mathrm{Z}$ & 1000 & 0.004 & 250.00 \\
\hline
\end{tabular}

According to the results of stiffness analysis, the stiffness in direction $\mathrm{X}$ is the smallest, which is consistent with the harmonic response analysis. Therefore, it is necessary to reinforce the equipment in direction $\mathrm{X}$.

\section{Improvement scheme and analysis}

According to the modal analysis, harmonic response analysis and stiffness analysis of the equipment, the transverse fundamental frequency of the equipment is about $35 \mathrm{~Hz}$, which is close to the working frequency of the motor, and there is a risk of resonance. And the whole equipment reaches about $62 \mathrm{KN} / \mathrm{mm}$ in the transverse direction, carries low stiffness and large deformation under the transverse load; the longitudinal fundamental frequency of the equipment is $48 \mathrm{~Hz}$, which is very close to the working frequency, causing great risk of resonance.

Based on the experiment and the installation space of the equipment, the following modifications are recommended, as shown in figure 7 represents the condition after another meshing.

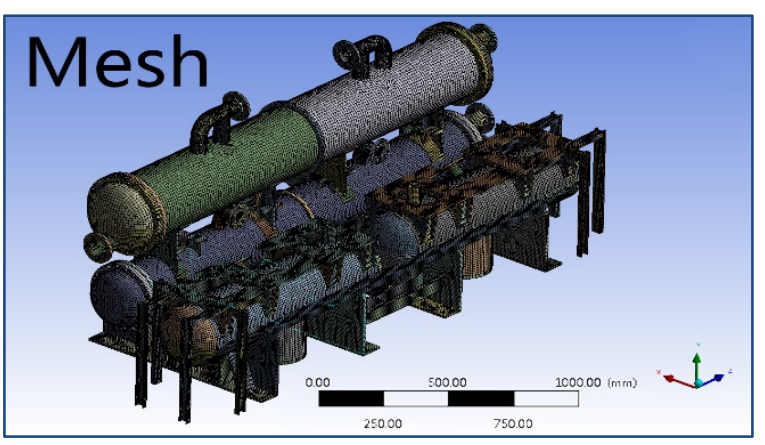

Figure7 Improved finite element model

\subsection{Modal analysis after transformation}

The modal analysis of the improved chiller shows that the first natural frequency is about $39 \mathrm{~Hz}$, the second one $62 \mathrm{~Hz}$, the third one $72 \mathrm{~Hz}$, the fourth one $88 \mathrm{~Hz}$, the fifth one $123 \mathrm{~Hz}$. The overall stiffness of the equipment has been improved, and the lateral stiffness of the equipment has remarkable enhancement.

\subsection{Harmonic response analysis after transformation}

We analyze the harmonic response of the chiller in the range of $0 \mathrm{~Hz}$ to $120 \mathrm{~Hz}$. After applying the same load as before, the harmonic response analysis results are basically consistent with the spectrum analysis results. The maximum frequency band of displacement response is located in the corresponding frequency band of each order mode of the equipment. The maximum response displacement in all directions has reduced to a certain extent, and the maximum response displacement of the transverse (direction $\mathrm{X}$ ) of the equipment at the fundamental frequency is reduced from $0.56 \mathrm{~mm}$ to 0.056 $\mathrm{mm}$ before the transformation, which is decreased by $90 \%$, and shows the largest reduction. It can be qualitatively judged that the transformation is effective for the vibration reduction of the equipment.

\subsection{Stiffness analysis of the transformed equipment}

The same static load is applied at the center of the four bolt holes of the motor installation as before. Before transformation, the transverse (direction X) stiffness of the equipment stays at $62.5 \mathrm{KN} / \mathrm{mm}$, increased by $23 \%$; the vertical (direction $\mathrm{Y}$ ) stiffness is $333.33 \mathrm{KN} / \mathrm{mm}$, increased by $54 \%$; the longitudinal (direction $\mathrm{Z}$ ) stiffness stays at $250 \mathrm{KN} / \mathrm{mm}$ before the transformation, and the stiffness increased by $29 \%$. After the transformation, the stiffness has been significantly enhanced. Because of the addition of four vertical supports on one side, the vertical increase represents the most evident one.

\subsection{Seismic analysis of equipment after transformation}

According to the spectrum analysis, the fundamental frequency of the equipment is $39 \mathrm{~Hz}$, which is basically the same as the cut-off frequency of the floor response spectrum. And adopting the 1.5 times of zero period acceleration for seismic analysis. According to the numerical simulation, the maximum stress of the equipment is mainly concentrated in the nozzle, corner, reinforcement and other positions. This position belongs to the geometric discontinuity area, which is mainly manifested as the peak stress. After removing the discontinuity area within the scope of $\sqrt{R \times t}$, the evaluation results of each component are shown in table 3 .

Table 3 Stress intensity assessment

\begin{tabular}{|c|c|c|c|c|c|c|}
\hline $\begin{array}{c}\text { Equipm } \\
\text { ent }\end{array}$ & $\begin{array}{c}\text { Compon } \\
\text { ent }\end{array}$ & $\begin{array}{c}\text { Evaluation } \\
\text { criteria }\end{array}$ & $\begin{array}{l}\text { Stress } \\
\text { type }\end{array}$ & $\begin{array}{c}\text { Calculated } \\
\text { value } \\
(\mathrm{MPa})\end{array}$ & $\begin{array}{c}\text { Evaluation } \\
\text { limits } \\
(\mathrm{MPa})\end{array}$ & $\begin{array}{c}\text { Stress } \\
\text { ratio }\end{array}$ \\
\hline \multirow{8}{*}{$\begin{array}{c}\text { evaporat } \\
\text { or }\end{array}$} & \multirow{2}{*}{ tanker } & \multirow{8}{*}{$\begin{array}{l}\text { class } \mathrm{O} \\
\text { criteria }\end{array}$} & $\sigma \mathrm{m}$ & 69.99 & 127.5 & 0.55 \\
\hline & & & $\sigma \mathrm{m}+\sigma \mathrm{b}$ & 91.51 & 191.25 & 0.48 \\
\hline & \multirow{2}{*}{$\begin{array}{c}\text { sealing } \\
\text { head }\end{array}$} & & $\sigma \mathrm{m}$ & 70.94 & 127.5 & 0.56 \\
\hline & & & $\sigma \mathrm{m}+\sigma \mathrm{b}$ & 77.23 & 191.25 & 0.40 \\
\hline & \multirow{2}{*}{ flange } & & $\sigma \mathrm{m}$ & 80.40 & 127.5 & 0.63 \\
\hline & & & $\sigma \mathrm{m}+\sigma \mathrm{b}$ & 83.44 & 191.25 & 0.44 \\
\hline & \multirow{2}{*}{$\begin{array}{c}\text { supporti } \\
\text { ng part }\end{array}$} & & $\sigma \mathrm{m}$ & 46.27 & 92.25 & 0.50 \\
\hline & & & $\sigma \mathrm{m}+\sigma \mathrm{b}$ & 55.08 & 138.38 & 0.40 \\
\hline \multirow{3}{*}{$\begin{array}{c}\text { condens } \\
\text { er }\end{array}$} & \multirow{2}{*}{ tanker } & \multirow{3}{*}{$\begin{array}{l}\text { class O } \\
\text { criteria }\end{array}$} & $\sigma \mathrm{m}$ & 51.65 & 127.5 & 0.41 \\
\hline & & & $\sigma \mathrm{m}+\sigma \mathrm{b}$ & 87.34 & 191.25 & 0.46 \\
\hline & sealing & & $\sigma \mathrm{m}$ & 48.67 & 127.5 & 0.38 \\
\hline
\end{tabular}




\begin{tabular}{|c|c|c|c|c|c|c|}
\hline & head & & $\sigma \mathrm{m}+\sigma \mathrm{b}$ & 56.05 & 191.25 & 0.29 \\
\hline & & & $\sigma \mathrm{m}$ & 27.22 & 127.5 & 0.21 \\
\hline & & & $\sigma \mathrm{m}+\sigma \mathrm{b}$ & 27.49 & 191.25 & 0.14 \\
\hline & supporti & & $\sigma \mathrm{m}$ & 23.15 & 92.25 & 0.25 \\
\hline & ng part & & $\sigma \mathrm{m}+\sigma \mathrm{b}$ & 28.46 & 138.38 & 0.21 \\
\hline & & & $\sigma \mathrm{m}$ & 109.26 & 127.50 & 0.86 \\
\hline & & & $\sigma \mathrm{m}+\sigma \mathrm{b}$ & 167.76 & 191.25 & 0.88 \\
\hline oil & sealing & class $\mathrm{O}$ & $\sigma \mathrm{m}$ & 53.83 & 127.50 & 0.42 \\
\hline on tank & head & criteria & $\sigma \mathrm{m}+\sigma \mathrm{b}$ & 59.99 & 191.25 & 0.31 \\
\hline & supporti & & $\sigma \mathrm{m}$ & 83.71 & 92.25 & 0.91 \\
\hline & ng par & & $\sigma \mathrm{m}+\sigma \mathrm{b}$ & 97.71 & 138.38 & 0.71 \\
\hline
\end{tabular}

\section{Optimization results and analysis}

According to the analysis, the overall transverse and longitudinal stiffness of the chiller is relatively low. There is a resonance risk in the range of the operating frequency of the basic frequency displacement motor $(30 \mathrm{~Hz}$ to $70 \mathrm{~Hz})$ of the two directions. We should select the unit with high vibration in operation and strengthen the equipment foundation for the weak points.

After the improvement, the vibration test of the equipment is carried out, and the test results are shown in Table 4.

Table 4 Vibration test comparison of refrigeration unit before and after transformation

\begin{tabular}{|c|c|c|c|c|c|c|}
\hline $\begin{array}{c}\text { Equipm } \\
\text { ent }\end{array}$ & $\begin{array}{c}\text { Measurem } \\
\text { ent }\end{array}$ & $\begin{array}{c}\mathrm{MBN} \\
\mathrm{D}-1 \\
\end{array}$ & $\begin{array}{c}\text { MBN } \\
\mathrm{D}-2\end{array}$ & $\begin{array}{l}\text { MB } \\
\text { D-1 }\end{array}$ & $\begin{array}{l}\text { MB } \\
\text { D-2 }\end{array}$ & $\begin{array}{l}\text { MB } \\
\text { D-3 }\end{array}$ \\
\hline \multirow{2}{*}{$\begin{array}{l}\text { motor } 1 \\
\text { of } \\
\text { refrigera } \\
\text { tor }\end{array}$} & $\begin{array}{c}\text { before } \\
\text { transforma } \\
\text { tion }\end{array}$ & 2.94 & 3.22 & 3.06 & 0.93 & 3.96 \\
\hline & $\begin{array}{c}\text { after } \\
\text { transforma } \\
\text { tion }\end{array}$ & 2.04 & 1.25 & 2.17 & 0.74 & 0.75 \\
\hline $\begin{array}{c}\text { vibratio } \\
n \\
\text { standard }\end{array}$ & \multicolumn{6}{|c|}{ alarm value: $4.5 \mathrm{~mm} / \mathrm{s}$; shutdown value: $7.1 \mathrm{~mm} / \mathrm{s}$} \\
\hline
\end{tabular}

The test results show that the improved scheme has obvious improvement effect on the vibration of the equipment.

\section{Conclusion}

In this paper, through modal analysis, harmonic response analysis, stiffness analysis and strength analysis of chillers, a complete analysis process of vibration analysis and scheme formulation of chillers in nuclear power plant was established. ANSYS Workbench software was used to simulate the frequency of the equipment under different modal orders, calculate and analyze the harmonic response and stiffness weak points of the equipment, and study the stress of the equipment under different loads. In the process of theoretical calculation, we added the knocking test of equipment fixed frequency analysis to accurately verify the validity of the model. According to the results of stiffness calculation, the weak points of the equipment were precisely found out, and then the foundation reinforcement measures were carried out based on the position. Finally, we calculated and analyzed the effectiveness of the reinforcement measures in enhancing the stiffness. In addition, the seismic analysis and evaluation of the equipment were carried out again, and the seismic grade of the equipment was not reduced due to the optimization scheme. The scheme was convenient for efficient, accurate and economic evaluation of vibration problems of similar rotating equipment in power plant, and provided accurate reference and complete analysis system for equipment vibration improvement scheme. The modal analysis method can be used to evaluate the vibration problems caused by the operation of similar units in the nuclear power plant.

\section{Reference}

1. Cao Yanyan, Zhao Dengfeng. Finite element modal analysis theory and its application [J]. Mechanical engineering and automation, 2007, 000 (001): 73-74.

2. Su Linsen, Yang Huiyu, etc. Devices and systems of 900 MW PWR [M], Guangdong: Guangdong Nuclear Power Training Center, 2000.

3. Ni Qingliang. Modal analysis and synchronous control of dual excitation system [D]. 2014.

4. Bai Song, Xu Xinxi, Tan Shulin, etc. Finite element modeling and modal analysis of an ambulance carriage [J]. Machinery and Electronics, 2010(S1): 77-79.

5. Jianfei K, Bingli Z, Meng C , et al. EXPERIMENTAL MODAL ANALYSIS AND NUMERICAL SIMULATION OF THE ARTILLERY RECOILING PARTS [J]. Mechanics in Engineering, 2006, 28(1):65-68.

6. Yang Kang, Han Tao. Application of ANSYS in modal analysis [J]. Journal of Jiamusi University (Natural Science Edition), 2005, 23(1): 81-84.

7. Zhang Xueliang. Study on Modal Analysis Structure Optimization Method of Gearbox [D]. Taiyuan University of Technology, 2010. 